\title{
BIOCARVÃO DO BIOSSÓLIDO DA ESTAÇÃO DE TRATAMENTO DE ESGOTO DE PRESIDENTE PRUDENTE-SP
}

\section{BIOCHAR OF THE STS'S BIOSOLID OF THE PRESIDENTE PRUDENTE}

Evelin Koyama Paulino ${ }^{1}$, Melissa Arantes Pinto ${ }^{1}$, Daniel Ângelo Macena ${ }^{2}$, Angelica Caroline Lima ${ }^{1}$, Elida Moreira de Lima Santana ${ }^{1}$, Janardelly Gomes De Souza ${ }^{1}$, Marcelo Rodrigo Alves ${ }^{1}$

${ }^{1}$ Universidade do Oeste Paulista - UNOESTE. ${ }^{2}$ Universidade Virtual do Estado de São Paulo - UNIVESP.

E-mail: marceloalves@unoeste.br

RESUMO - O biossólido é um material rico em matéria orgânica e outros nutrientes de importância agronômica como nitrogênio e fosfóro. O seu fim quase sempre é em aterros sanitários. Portanto, sua transformação em biocarvão, pelo processo de pirólise, seria uma forma de associar seus benefícios inerentes ao biocarvão, possibilitando um destino final mais adequado. Diante disto o trabalho teve como objetivo produzir o biocarvão a fim de avaliar a viabilidade de uso na agricultura. O biocarvão foi produzido em escala laboratorial, em diferentes temperaturas e por conseguinte foi realizada a caracterização do produto final. Como resultado, o material comprovou ser rico em matéria orgânica conforme aumento da temperatura, afinando o material e aumento da superfície específica tornando $\mathrm{o} \mathrm{pH}$ alcalino servindo como sequestro de carbono. Desta forma, com a preocupação constante da produção do lodo de esgoto, o biocarvão se mostrou mais eficiente do que o biossólido puro para aplicação na agricultura.

Palavras-chave: Biocarvão; Lodo de Esgoto; Condicionador de Solo.

ABSTRACT - Biosolid is a material rich in organic matter and other nutrients of agronomic importance such as nitrogen and phosphorus. Its end is almost always in landfills. Therefore, its transformation into biochar by the pyrolysis process would be a way to associate its inherent benefits to biochar, enabling a more appropriate final destination. Given this work the objective was to produce biochar in order to evaluate the viability of use in agriculture. The biochar was produced on a laboratory scale at different temperatures and therefore the characterization of the final product was performed. As a result, the material has proven to be rich in organic matter as temperature increases, thinning the material and increasing the specific surface making the alkaline $\mathrm{pH}$ serving as carbon sequestration. Thus, with the constant concern of sewage sludge 
production, biochar proved to be more efficient than pure sewage sludge for agricultural application.

Keywords: Biochar; Sewage Sludge; Soil Conditioner. 


\section{INTRODUÇÃO}

O biossólido é um resíduo sólido rico em matéria orgânica resultante de águas residuais nas Estações de tratamento de Esgotos (ETEs). Entretanto, sua disposição final tornou-se um grande desafio, pois a quantidade produzida aumenta proporcionalmente que a população cresce (LOBO; GASSI FILHO; KUMMER, 2014).

Grande parte do lodo gerado ainda é disposto em rios ou em aterros sanitários (KATAYAMA, et al., 2015), o que representa risco á saúde pública e ao meio ambiente (HWANG, et al., 2007).

Um possível uso final para o lodo é sua aplicação em solos agrícolas como condicionador de solos para áreas degradadas, uma vez que possui apreciáveis quantidades de matéria orgânica e de nutrientes que são essências para o desenvolvimento vegetal (BEZERRA et al., 2006; TAMANINI et al., 2008, BITTENCOURT et al., 2017).

No Brasil, este uso é regulamentado pela resolução $n^{\circ} 375$ do Conama, que define critérios e procedimentos para o uso agrícola de lodos de esgoto gerados em estação de tratamento de esgoto sanitário e seus produtos derivados (conselho nacional do meio ambiente - CONAMA, 2006). Esta resolução regulamenta os níveis seguros de doses de aplicação no solo (PIRES e ANDRADE, 2014). Além disso, os lodos também contêm organismos patogênicos que podem causar contaminação ambiental (POGGIANI; GUEDES; BENEDETTI, 2000).

Diante disso, uma alternativa ao uso do biossólido, é sua transformação em biocarvão pelo processo de pirolise, o que, segundo Liu, Liu e Zhang (2014), reduzem a quantidade de agentes patogênicos, bem como a disponibilidade de contaminantes, o que melhora a qualidade do resíduo orgânico e possibilita sua aplicação no solo como condicionante, além de ser uma alternativa vantajosa, principalmente do ponto de vista ambiental, quando se comparado a outras práticas de destinação final.

Embora rico em nutrientes e matéria orgânica, encontrar um destino racional e sustentável para o biossólido, passou a ser um desafio para vários segmentos de pesquisa. Em contrapartida, existem no Brasil milhares de hectares de solos degradados com baixa fertilidade e assim fica evidente a importância de encontrar uma maneira segura e viável do uso do lodo de esgoto como condicionador de solos, de modo que isso possa representar ganhos econômicos, sociais e ambientais.

Desta forma, o presente artigo teve como objetivo principal produzir biocarvão a partir do lodo de esgoto gerado na ETE de Presidente Prudente, além de proceder a sua caracterização, física e química de maneira que se possa avaliar a sua viabilidade de uso na agricultura.

\section{METODOLOGIA}

O lodo de esgoto utilizado neste trabalho foi proveniente da Companhia de Saneamento Básico do Estado de São Paulo SABESP, unidade de Presidente Prudente. Tal material é obtido por processo aeróbico, sendo considerado lodo ativado e submetido a secagem térmica do resíduo para redução dos patógenos e classificado como classe $A$, segundo CONAMA 357 de 2006. Foi utilizado o delineamento com 4 repetições. Os tratamentos foram constituídos pelo biossólido puro e por três biocarvões obtidos em três temperaturas diferentes que foram definidos com base nas análises termogravimétricas (Figura 1). 
Figura 1. Curva termogravimétrica (TG, escala à esquerda) e derivada da curva termogravimétrica (DTG, escala à direita) do Biossólido em razão de aquecimento de $10^{\circ} \mathrm{C} / \mathrm{min}$.

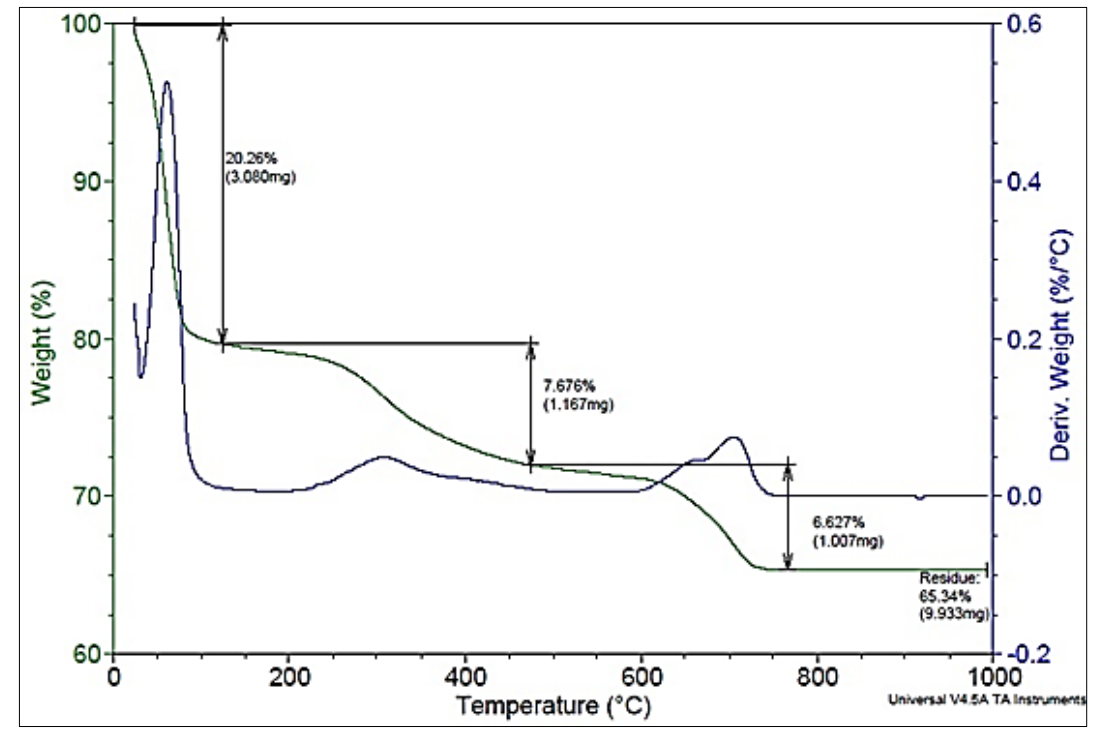

Fonte: $\mathrm{O}$ autor.

Para o preparo do biocarvão pesou-se em uma balança semi-analitica $600 \mathrm{~g}$ de biossólido peneirado a $200 \mathrm{~mm}$, em seguida transferido ao reator para realização da pirólise. Após vedar o reator foi posicionado no interior do forno mufla e induzido a temperatura ajudada em 100 ㄷ. Com a estabilização da temperatura em $100^{\circ} \mathrm{C}$, foi reajustada na temperatura de dosagem de acordo com cada tratamento e introduzida a mangueira de silicone acoplada em um condensador reto com auxílio de ciclo de água para condensação de líquido pirolenhoso no processo de queima e um béquer para coletar o material condensado. Após a estabilização da temperatura, foi cronometrada um tempo de 30 minutos de pirólise. $O$ liquido pirolenhoso foi armazenado e acondicionado em refrigerador comum. O material pirolisado foi retirado do reator e pesado antes e após a pirolise, aplicando o balanço de massas para definir o rendimento gravimétrico. As análises imediatas foram realizadas conforme a Norma 8112 da Associação Brasileira de Normas Técnicas (ABNT 1986), na qual foi determinado os teores de materiais voláteis e de cinzas e, por diferença, o teor de carbono fixo do material.
As análises de potencial hidrogeniônico $(\mathrm{pH})$ e de condutividade elétrica (C.E.) foram determinadas, segundo a metodologia proposta por Rajkovich et al. (2011). A capacidade de troca de cátions (CTC) efetiva das amostras foi determinada conforme o método oficial do Ministério da Agricultura, Pecuária e Abastecimento (MAPA) para fertilizantes orgânicos (BRASIL, 2007). Para a determinação da densidade de partículas (Dp), ou densidade real, foi utilizado $20 \mathrm{~g}$ do material pirolisado (seco a $105^{\circ} \mathrm{C}$ ) em um erlenmeyer de $50 \mathrm{ml}$ que, posteriormente, foi completado com álcool etílico, até atingir seu volume total (EMBRAPA, 1997). Para determinação das frações granulométricas dos biocarvões produzidos foi utilizado, em cada procedimento, 100 gramas dos respectivos materiais que foram colocados na parte superior de um jogo de peneiras granulométricas de Mesh contendo 5 peneiras com as seguintes malhas:2; 1,19; 0,$59 ; 0,25$ e $0,149 \mathrm{~mm}$. As peneiras foram submetidas a um agitador de peneiras a 10 rpm por 15 minutos. Em seguida o material retido em cada peneira foi transferido para um recipiente numerado e de peso conhecido, levado para estufa de secagem e esterilização a $105^{\circ} \mathrm{C}$. Outros $100 \mathrm{~g}$ de 
amostra foi levado para estufa a fim de determinar o peso após secagem a $105^{\circ} \mathrm{C}$ para utilização no cálculo das frações granulométricas (EMBRAPA, 1997).
Conforme o gráfico 1 , para as porcentagens da massa seca, houve uma queda de $8,91 \%$ de BC200 para o BC550 e, por outro lado entre BC550 e BC750 houve só $1,87 \%$ de queda.

\section{RESULTADOS E DISCUSSÃO}

\subsection{BALANÇO DE MASSAS}

Gráfico 2. Resultados do Balanço de Massas.

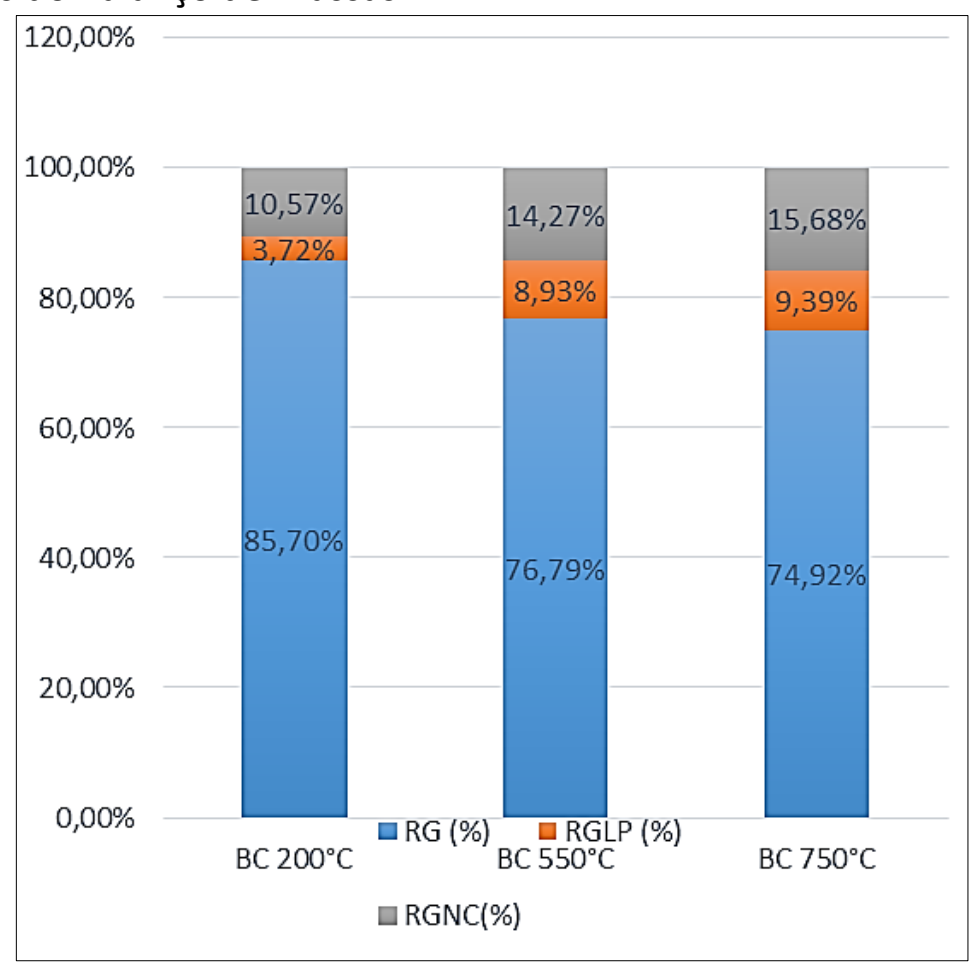

Fonte: $\mathrm{O}$ autor.

Nota: $\mathrm{BC}=$ Biocarvão; $\mathrm{RG}=$ Rendimento Gravimétrico; $\mathrm{RGLP}=$ Rendimento Gravimétrico do Líquido Pirolenhoso e RGNC = Rendimento Gravimétrico em Gases Não Consideráveis.

Comparado aos valores da massa seca, o liquido condensável adquiriu resultados inversamente proporcionais, na qual conforme ocorria o aumento da temperatura nos diferentes tratamentos, 0 seu valor de rendimento gravimétrico de licor pirolenhoso constatou um aumento considerável de 5,21\% entre o BC200 e BC500. Por outro lado, entre BC500 e o BC750 houve um aumento muito baixo no valor de $0,46 \%$. Semelhante ao RGLP (\%), os valores de $\mathrm{RGNC}(\%)$ também demonstraram um aumento conforme a temperatura subia.

\subsubsection{RENDIMENTO GRAVIMÉTRICO}

Pode-se verificar que existe um decréscimo mais acentuado do rendimento gravimétrico em temperaturas mais baixas e na medida em que se aumenta a temperatura final de carbonização, parece haver tendência de estabilização (TRUGILHO;SILVA, 2001). Nos 3 tratamentos, entre $B C 200$ e BC550 houve um grau de diminuição maior que entre $\mathrm{BC5} 50$ o BC750. Isso quer dizer que entre BC550 e BC750 o RG (\%) teve uma estabilização, não sendo, portanto necessário submeter a temperaturas maiores do que $750^{\circ} \mathrm{C}$ para obter um biocarvão com alto teor de carbono.

Contudo, é importante analisar o Rendimento Gravimétrico para identificar a temperatura ideal de se obter um biocarvão com o maior teor de carbono, sem 
comprometer um rendimento aceitável (GUILHEN, 2018).

Comparando com o tratamento de Veiga (2016), em que constou também a diminuição do RG (\%), porém com um grau de diminuição maior em uma temperatura constante. Segundo Guilhen (2018), vários estudos mostraram que o teor de carbono aumenta conforme o aumento da temperatura pirolítica.

Com o aumento da temperatura ocorre um aumento de degradação na pirólise (MASEK et al., 2013), podendo apresentar variáveis de acordo com o material de uso, influenciando a perda de massa. Sustentando esta afirmação, compostos de dejeto animal possui uma heterogeneidade, acelerando o processo em comparação aos compostos de base orgânica (CONZ, 2015).

A queda de rendimento em temperaturas acima de $400^{\circ} \mathrm{C}$ demonstra que seja decorrente da volatilização de alguns elementos em que consistem no composto. Conforme Hossain et al. (2010), a elevação da temperatura, por mais que seja mínima, ocasiona na diminuição de volume de nitrogênio. A volatilização de nutrientes como nitrogênio, potássio e enxofre, em biomassas de casca de café, aumenta em altas temperaturas, assim como o teor de cinzas, e ocasiona a redução no teor de carbono fixo.

\subsubsection{RENDIMENTO GRAVIMÉTRICO DE LICOR PIROLENHOSO}

$\mathrm{Na}$ pirólise de $200^{\circ} \mathrm{C}$ foi o que mostrou menor rendimento gravimétrico de licor pirolenhoso se comparando ao de $550^{\circ} \mathrm{C}$ e $750^{\circ} \mathrm{C}$. Assim fica evidente que o RGLP (\%) fica maior conforme aumenta a temperatura de pirólise do biossólido do lodo de esgoto.

\subsubsection{RENDIMENTO GRAVIMÉTRICO EM GASES NÃO CONDENSÁVEIS}

O biossólido do lodo de esgoto apresentou um maior rendimento em gases não condensáveis à medida que houve uma elevação da temperatura final diferenciando em cada tratamento. Veiga (2016), obteve os mesmos resultados, onde o RGNC(\%) apresentou-se maior, conforme a temperatura final aumentou.

\subsection{ANÁLISE IMEDIATA}

Para Conz (2015) (apud MITCHELL et al., 2013), a análise imediata separa os componentes da biomassa (i.e.: umidade, material volátil, teor de cinzas e carbono fixo) para avaliar a variação em suas proporções nos diferentes materiais formados pelo processo de transformação térmica. 
Gráfico 2. Proporção relativa dos componentes da biomassa.

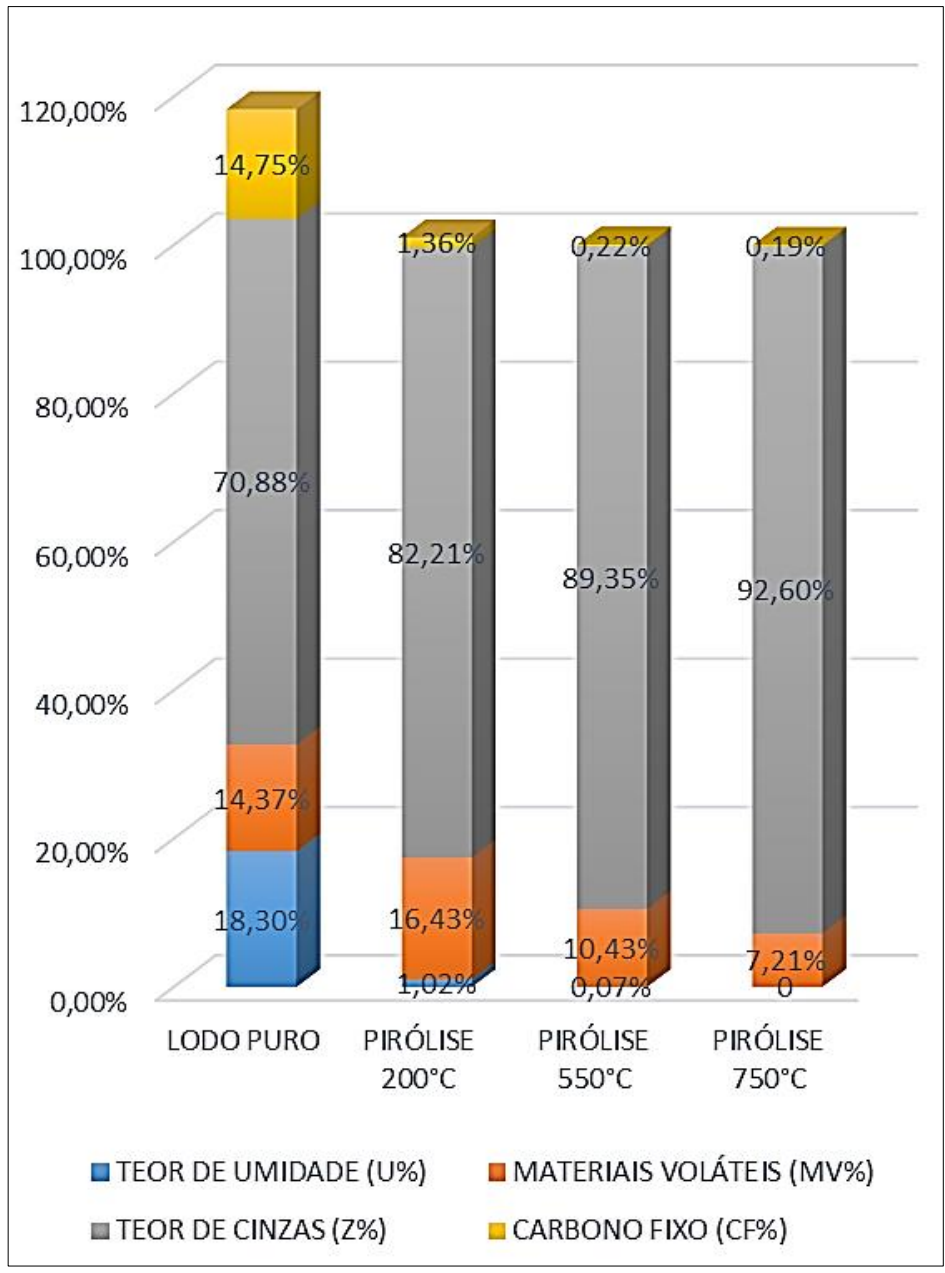

Fonte: Próprio autor.

Como esperado de um material pirolisado, observou-se valores de umidades próximos a 0 , alto teor de cinzas em média de $88,05 \%$ e queda constante nas análises de materiais voláteis e carbono fixo (Gráfico 2).

\subsubsection{TEOR DE UMIDADE}

Pode-se observar que nos três tratamentos de pirólise os teores de umidade (Gráfico 2) foram próximos de zero, não ultrapassando nem 1,05\%. Único que se mostrou diferente foi o controle, na qual obteve o valor de $18,30 \%$. Isso ocorre, uma vez que a partir de temperaturas de aproximadamente de $100^{\circ} \mathrm{C}$, inicia-se a perda da água do material. $\mathrm{O}$ próximo grau de perda é a partir do início da degradação de componentes de sua massa que seria a partir de $200^{\circ} \mathrm{C}$ (PIRES, 2017).

\subsubsection{TEOR DE MATERIAIS VOLÁTEIS}

De acordo com o Gráfico 2, o controle e a pirólise de $200^{\circ} \mathrm{C}$ se mostraram semelhante nos valores com uma diferença de $2,06 \%$, porém a medida que a temperatura da pirólise aumentou, houve um decréscimo nos valores de materiais voláteis, e isso significa que quanto maior a temperatura, maior a liberação de compostos voláteis (PINHEIRO et al., 2005). Esse comportamento é coerente e esperado, uma vez que os materiais voláteis tendem a ser liberados conforme submetidos a temperaturas mais altas (GUILHEN, 2018).

\subsubsection{TEOR DE CINZAS}

O teor de cinzas está relacionado ao conteúdo de nutrientes presentes no material (CONZ, 2015). Conforme analisado no Gráfico 2, pode ver um aumento gradativo no teor de cinzas juntamente com o aumento 
da temperatura pirolítica. Essa parcela é determinada quando todos os elementos orgânicos são volatizados após a completa combustão do mesmo (ENDERS et al., 2012).

O teor de cinzas está relacionado com a presença de quantidades e de qualidades diferentes de minerais presentes na biomassa, assim minerais como cálcio, potássio, fósforo, magnésio, ferro, sódio, entre outros, fazem aumentar o teor de cinzas (VALE et al., 2007). Os resultados observados no projeto de Conz (2015), os dejetos de galinha e seus biocarvões, apresentaram maior teor de cinzas pois é um material com maior valor de soma de nutrientes que é um composto orgânico semelhante ao Lodo de esgoto.

\subsubsection{TEOR DE CARBONO FIXO}

O carbono fixo é o material que não constitui material volátil, umidade ou cinzas. Portanto é o elemento que se mostra mais resistente após a pirólise (CONZ, 2015).
O máximo de teor de carbono alcançado foi no lodo puro, no valor de $14,75 \%$ e nos tratamentos de pirólise apresentaram valores muito baixos conforme a temperatura aumentava. $\mathrm{O}$ teor de carbono fixo mostrou-se baixo dessa maneira por causa do teor de cinzas que foi alto mostrando assim, uma relação entre eles. $\mathrm{Na}$ dissertação de Conz (2015), a serragem apresentou dominância no teor de carbono fixo, diferentemente do dejeto de galinha que apresentou menor teor de carbono fixo.

Na pesquisa de Veiga (2016), para os biocarvões da casca de café, observa-se forte queda do teor de carbono fixo, na temperatura de $550^{\circ} \mathrm{C}$, justamente onde for relatado elevado teor de cinzas e estabilização dos componentes voláteis para o mesmo, indicando que o comportamento do teor de cinzas e matérias voláteis refletiu no comportamento do teor de carbono fixo.

\subsection{POTENCIAL HIDROGENIÔNICO}

Gráfico 3. Potencial Hidrogeniônico do controle e tratamentos

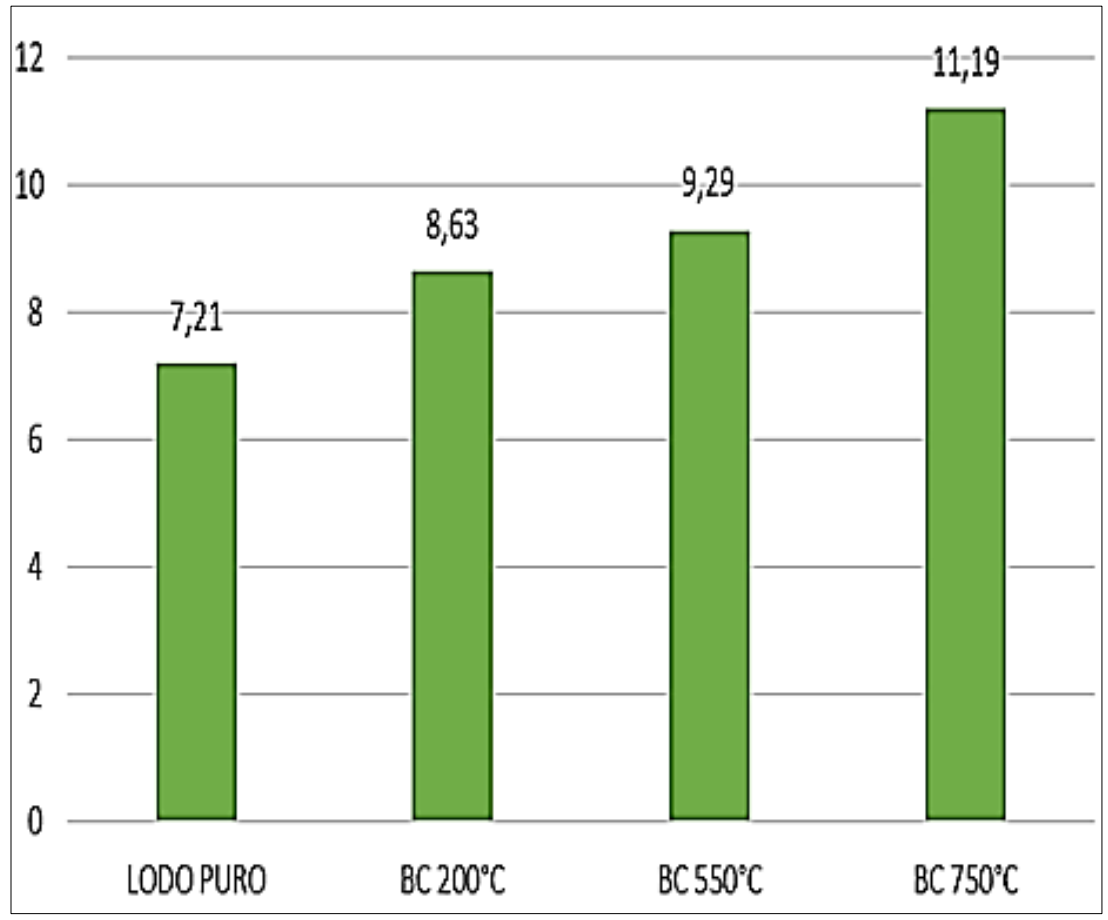

Fonte: $\mathrm{O}$ autor. 
Enquanto o lodo puro apresenta $\mathrm{pH}$ neutro, os tratamentos de pirólise mostraram-se todos alcalino, aumentando de valor conforme eleva a temperatura. Isso significa que o biocarvão em temperaturas altas como $550^{\circ} \mathrm{C}$ e $750^{\circ} \mathrm{C}$, se mostra melhor do que as outras pirólises analisadas, podendo ser usada para tamponar solo ácido.

A elevação dos valores de $\mathrm{pH}$ nos biocarvões é resultado das maiores concentrações de elementos alcalinos, tais como: $\mathrm{Na}, \mathrm{Ca}$ e $\mathrm{Mg}$; concentração essa favorecida pela crescente volatilização dos elementos C, H, O e N (GASKIN et al., 2008; SINGH et al., 2010). O aumento do $\mathrm{pH}$ também induz a formação de óxidos metálicos na própria estrutura dos biocarvões, deixando os metais menos disponíveis. Já Devens (2015), trabalhando com biocarvões de material orgânico, e Zelaya (2016) com uma mistura de biossólido e bagaço de cana-de-açucar, identificaram níveis de $\mathrm{pH}$ acima da neutralidade, confirmando que quanto maior a concentração de matéria orgânica, mais elevados serão os níveis de alcalinidade das biomassas.

Para Veiga (2016), para corrigir solos ácidos, o recomendado é o biocarvão produzido na temperatura a partir do $700^{\circ} \mathrm{C}$, pela sua capacidade de neutralizar $\mathrm{o} \mathrm{pH}$, enquanto para solos alcalinos são recomendados os biocarvões produzidos em temperaturas baixas como o lodo puro.

\subsection{CONDUTIVIDADE ELÉTRICA (C.E.)}

A condutividade elétrica é usada para especificar o caráter elétrico do biocarvão e quanto mais íons, maior a condutividade elétrica. Joseph et al. (2010), diz que quanto maior for a temperatura de pirólise, maior será a condutividade elétrica, e consecutivamente a concentração de nutrientes.

Gráfico 4. Condutividade Elétrica do controle e tratamentos em $\mu \mathrm{S} / \mathrm{cm}$.

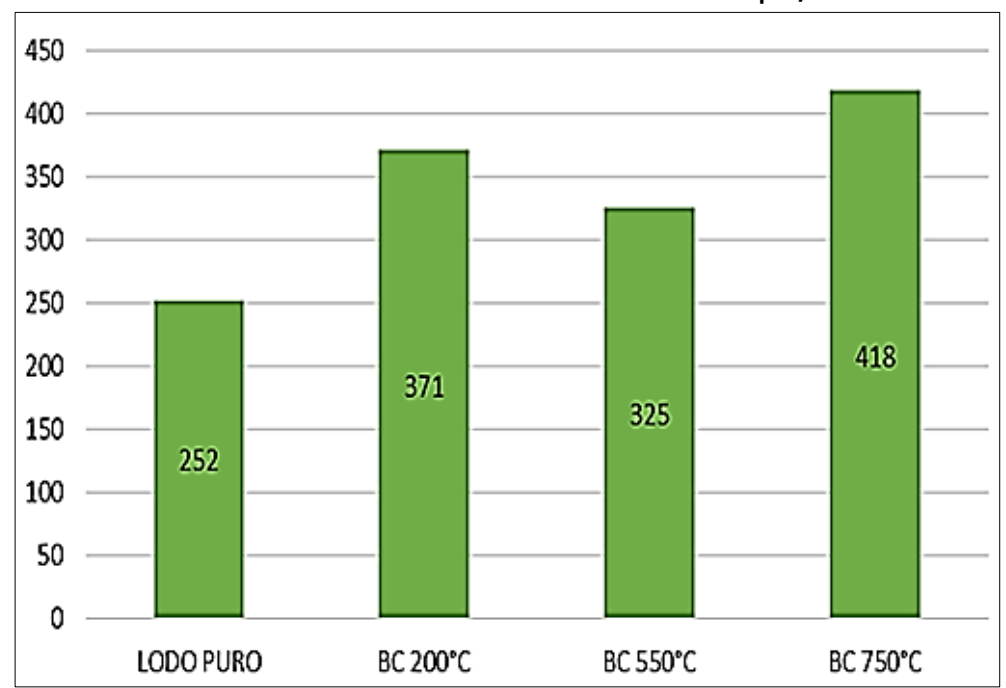

Fonte: $\mathrm{O}$ autor.

Observa-se que o valor da condutividade elétrica aumentou juntamente com a pirolização, com exceção no tratamento $\mathrm{BC} 550$, que demonstrou uma queda de $12,4 \%$ se comparando com o BC200.
Segundo Veiga (2016), revelou que na temperatura de $550^{\circ} \mathrm{C}$ houve uma queda similar como aconteceu nesse projeto. Conz (2015), também obteve tais resultados, e reforçou que se deve tomar cuidado e adquirir conhecimento dos elementos que possuem na matéria-prima, pois o mesmo 
fornecendo nutrientes ao solo pode ocasionar em possíveis contaminações do ambiente.

Em alguns estudos, demonstram que a C.E. aumenta junto com a temperatura e os biocarvão provenientes de resíduos animais contêm os maiores valores de condutividade. Dessa maneira, a C.E. mostra uma dependência com o conteúdo de nutrientes presentes na matéria prima (JOSEPH et al.,
2010) e Veiga (2016), relaciona os níveis elevados de C.E. com proporção relativa elevada no teor de cinzas.

\subsection{CAPACIDADE DE TROCA DE CÁTIONS (CTC)}

A capacidade de troca de cátions decai conforme a temperatura da pirólise aumenta (Gráfico 5).

Gráfico 5. Capacidade de Troca de Cátions do controle e tratamentos em mmol/Kg.

Fonte: Próprio autor.

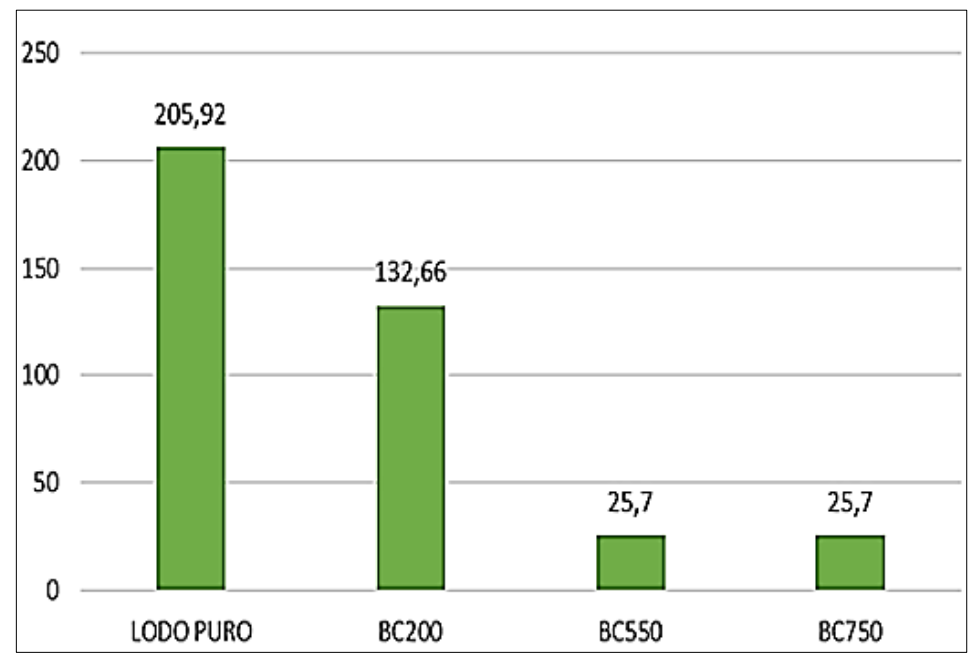

Percebe-se que o maior valor de CTC foi o da matéria prima $(205,92 \mathrm{mmol} / \mathrm{kg})$ e em seguida a capacidade de troca catiônica foi diminuindo conforme a temperatura aumentava, estabilizando de valor entre BC550 e BC750 no valor de $25,7 \mathrm{mmol} / \mathrm{kg}$.

Quanto maior o número de cargas que são negativas no biocarvão, maior será a sua capacidade de reter cátions. Sendo assim, Nobrega (2011) diz que a CTC é influenciada pela temperatura pirolítica, matéria prima utilizada e o pH. Valores mais baixos de CTC é observado em temperatura pirólitica mais altas devido á aromatização e a degradação dos grupos funcionais (GUILHEN, 2018).

Com o Gráfico 5, nota-se que o lodo puro apresenta uma capacidade de troca catiônica mais eficiente do que as pirólises, porém é importante salientar que mesmo os biocarvões apresentando CTC baixo, ele ainda continua sendo melhor na hora da sua aplicação, pois apresenta mais persistência no solo e pode contribuir para a CTC do meio por mais tempo quando comparado á sua matéria-prima de fácil degradação (CONZ, 2015).

\subsection{DENSIDADE DE PARTÍCULAS}

Com as amostras do biossólido seco á $105^{\circ} \mathrm{C}$ em estufa por $1,5 \mathrm{~h}$, variou-se pouco o volume de álcool etílico necessário para a realização da análise, variando em média $0,105 \mathrm{~g} / \mathrm{cm}^{3}$ nos tratamentos de pirólise.

Em geral, o aumento da temperatura deve causar a diminuição da densidade de partículas, mas nota-se que ela teve uma mudança muito mínima entre os tratamentos e a matéria-prima. Mostrando assim que não existem evidências apresentadas no presente estudo para confirmar a influência da temperatura na densidade de partículas dos biocarvões que foi o mesmo que apresentou no trabalho de Conz (2015). 
Gráfico 6. Densidade de partículas do controle e tratamentos em $\mathrm{g} / \mathrm{cm}^{3}$.

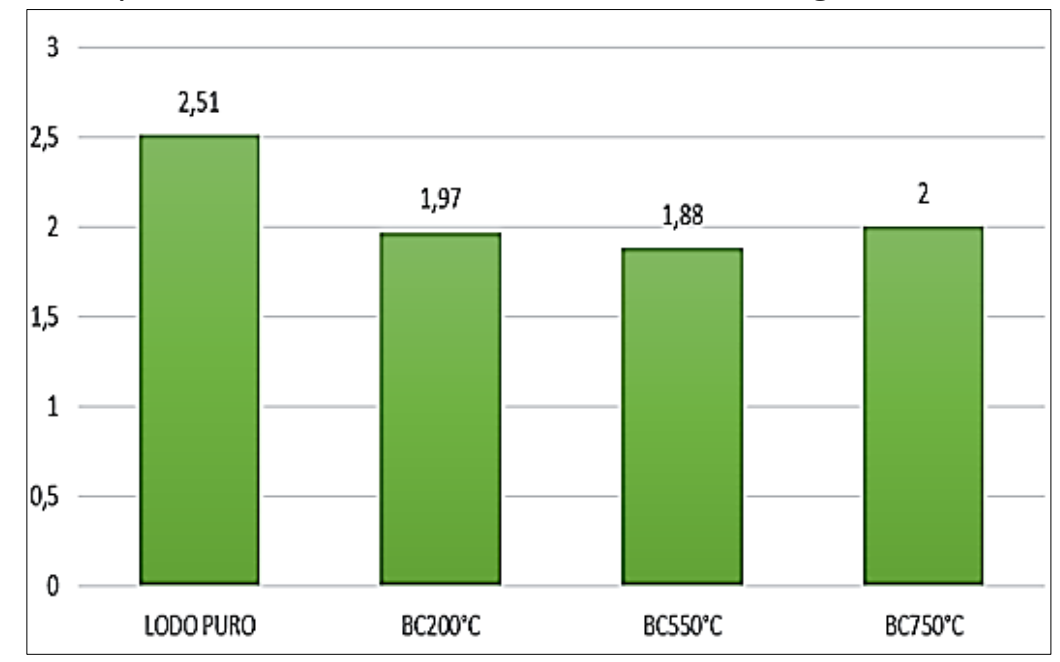

Fonte: Próprio autor.

\subsection{TEOR DE AGREGADO}

Gráfico 7. Teor de Agregado do controle e tratamentos em \%.

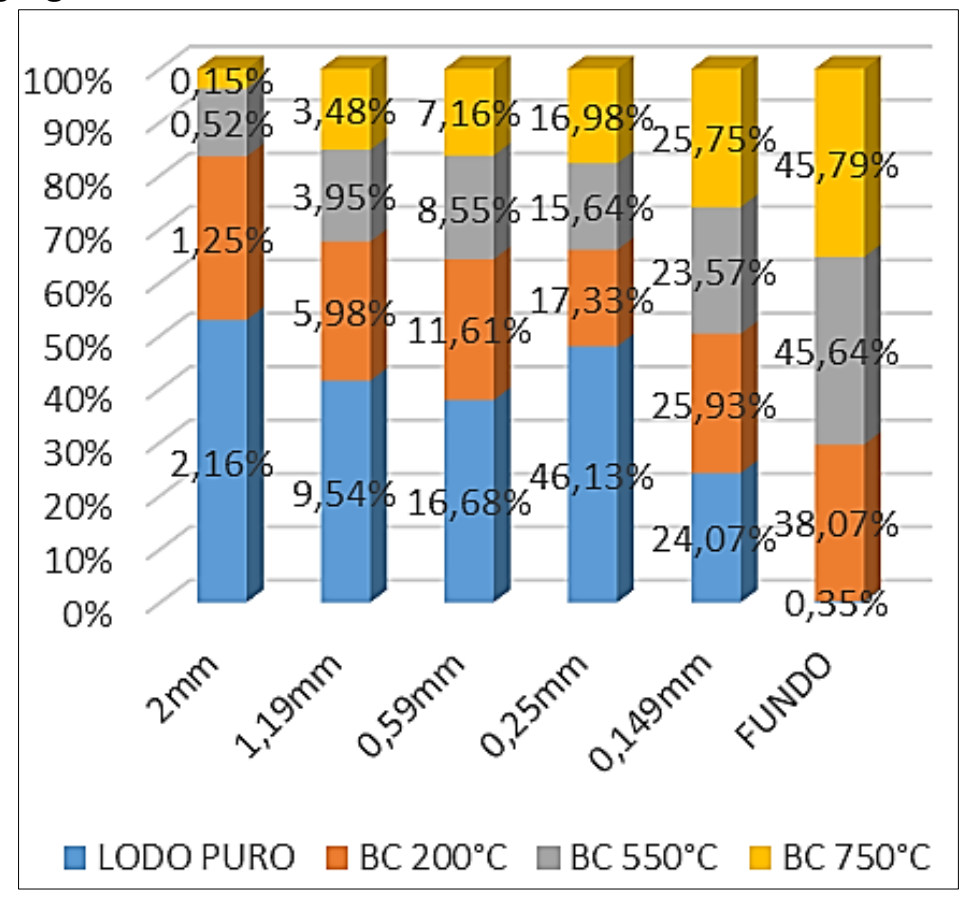

Fonte: Próprio autor.

Como pode observar, o lodo puro apresentou uma concentração significante de $46,12 \%$ na peneira de $0,25 \mathrm{~mm}$ e não sobrou pouco nas peneiras de $0,149 \mathrm{~mm}>$ fundo com uma concentração de $0,35 \%$. Por outro lado, os tratamentos de pirólises foram aumentando de concentração nas peneiras mais finas, se concentrando em média $43,2 \%$ no fundo.
De modo geral, Kim et al. (2013) diz que com a elevação da temperatura pirolítica, o material fica mais fino enfraquecendo a estrutura molecular e deixando o biocarvão mais vulnerável á quebra, aumentando a quantidade de partículas de dimensões menores. Assim, os biocarvões com partículas finas apresentam maior superfície de contato e específica com 
o solo, então vai conseguir interagir mais com o solo, retendo mais água e microrganismo presente no solo.

Mesmo Devens (2015), utilizando apenas 4 granulometrias no tamanho de suas partículas, encontrou valores semelhantes ao biocarvão de lodo de esgoto, pois ambos possuem uma resistência a quebra como demonstrado no mesmo. Mesmo aumentando $100^{\circ} \mathrm{C}$ em cada tratamento, a biomassa manteve-se constante apenas baixas variações. $O$ processo de pirólise mesmo que com pouco aumento de temperatura, interage com a quebra de partículas, tornando o material mais poroso e diminuindo a sua densidade.

\section{CONSIDERAÇÕES FINAIS}

Conclui-se que é evidente a preocupação com a destinação final do lodo de esgoto que vem crescendo a cada dia com o aumento desenfreado da população.

Assim com tantos hectares de solos degradados e o uso exagerado de adubo químico fez com que esse artigo ganhasse importância nos seus resultados, avaliando o seu uso como biocarvão, mostrando que a produção do biocarvão originada do biossólido, demonstrou aplicabilidade do seu uso na agricultura por ser melhor do que a sua matéria prima; serve como sequestro de carbono; podem ser utilizados para tamponar solos ácidos e equilibrar o $\mathrm{pH}$; um agregador de solo por ter alto teor de matéria orgânica e alto teor de nutrientes essenciais para o crescimento da planta e a construção do solo; apresenta ser mais estável se comparado ao biossólido que se degrada mais fácil, mantendo assim mais permanência no solo; pela maior superfície específica possibilita a retenção de líquido e dos microrganismos no solo.

Portanto é de suma importância a continuidade de análises mais a fundo, a fim de conhecer mais sobre o biocarvão e aplicar em campo para analisar como ele reage a longo prazo no solo para uma possível uso em fins agrícolas e ecológicos, representando ganhos econômicos, sociais e ambientais.

\section{AGRADECIMENTOS}

Os autores agradecem todos que colaboraram diretamente na execução e elaboração do trabalho e a Universidade do Oeste Paulista por todo o suporte técnico e financeiro, agradece também aos membros do Laboratório de Caracterização de Resíduos da Unesp de Presidente Prudente pela realização das análises termogravimétricas.

\section{REFERÊNCIAS}

AGRAFIOTI, E. et al. Biochar production by sewage sludge pyrolysis. Journal of Analytical and Applied Pyrolysis. p. 72-78, 2013.

https://doi.org/10.1016/j.jaap.2013.02.010

BETTIOL, W.; CAMARGO, O. A. A disposição de lodo de esgoto em solo agrícola. In: BETTIOL, W.; CAMARGO, O. A. Lodo de esgoto: impactos ambientais na agricultura. Jaguariúna: Embrapa Meio Ambiente,2006. , p. 25-36.

BEZERRA, F. et al. Lodo de esgoto em revegetação de área degradada. Pesquisa Agropecuária Brasileira, v. 41, n. 3, p. 469476, 2006. https://doi.org/10.1590/S0100204X2006000300014

BITTENCOURT, S.; et al. Gestão do uso agrícola do lodo de esgoto: estudo de caso do estado do Paraná, Brasil. Eng. Sanit. Ambient., Rio de Janeiro, v. 22, n. 6, p. 11291139, 2017. https://doi.org/10.1590/s1413$\underline{41522017156260}$

BRASIL, INSTRUÇÃO NORMATIVA SDA № 17, DE 21 DE MAIO 2007.

BRASIL. Resolução Conama no 375, de 29 de agosto de 2006. Define critérios e procedimentos, para o uso agrícola de lodos de esgoto gerados em estações de tratamento de esgoto sanitário e seus produtos derivados, e dá outras providências. Diário Oficial da União, Brasília, DF, 29 de Ago de 2006. Disponível em: 
http://www.mma.gov.br/port/conama/res/r es06/res37506.pdf. Acesso em: 7 mar. 2018.

CETESB - COMPANHIA DE TECNOLOGIA DE SANEAMENTO AMBIENTAL. Aplicação de Lodos de Sistemas de Tratamento Biológico em Áreas Agrícolas - Critérios para Projeto e Operação. Norma P.4.230 - São Paulo, agosto de 1999.

CONAMA, Resolução $n^{\circ}$ 375, de 29 de agosto de 2006, do Conselho Nacional do Meio Ambiente. Brasília: CANOMA, DF, 2006.

CONZ, R. Caracterização de matérias-primas e biochars para aplicação na agricultura. 2015. Dissertação (Mestrado) - Escola Superior de Agricultura "Luiz de Queiroz". Piracicaba, 2015. 132p.

COSTA, A. M. Influência das propriedades anatômicas, químicas e físicas da madeira de Eucalyptuse Corymbia na qualidade do carvão para uso siderúrgico. 2014. Tese (Doutorado em Ciência e Tecnologia da Madeira) -Universidade Federal de Lavras, Lavras, 2014.

COSTA, A.; COSTA, A. Manual de uso agrícola e disposição do lodo de esgoto para o Estado do Espírito Santo. Vitória, ES, Incaper, 2011. 126p.

DOWNIE, A.; CROSCKY, A.; MUNROE, P. Physical properties of biochar. In: LEHMANN, J.; JOSEPH, S. (ed.). Biochar for environmental management science and technology. London: Earthscan, 2009. p. 1329.

EMBRAPA. Centro Nacional de Pesquisa de Solos. Manual de métodos de análise de solo.2. ed. rev. atual. Rio de Janeiro: EMBAPA, 1997. 212p.

ENDERS, A. et al. Characterizationof biocarvões to evaluate recalcitrance and agronomic performance. Bioresource Technology, Oxford, v. 114, p. 644-653, June
2012.

https://doi.org/10.1016/i.biortech.2012.03.0 $\underline{22}$

GASKIN, J. W.; STEINER, C.; HARRIS, K.; DAS, K.C.;BIBENS, B. Effect of low-temperature pyrolysis conditions on biochar for agricultural use. Trans. Asabe, v. 51, p. 20612069, 2008.

https://doi.org/10.13031/2013.25409

GONZAGA, M., et al. Sewage sludge derived biochar and its effect on the growth and morphological traits of eucalyptus grandis w.hill ex maiden seedlings. Ciênc. Florest., Santa Maria, v. 28, n. 2, p. 687-695, 2018. ttps://doi.org/10.5902/1980509832067

HOSSAIN, M. et al. Agronomic properties of wastewater sludge biochar and bioavailability of metals in production of cherry tomato (Lycopersicon esculentum). Chemosphere, v. 78, p. 1167-1171, 2010. https://doi.org/10.1016/i.chemosphere.2010 .01 .009

HOSSAIN, M. et al. Influence of pyrolysis temperature on production and nutrient properties of wastewater sludge biochar. Journal of Environmental Management, v. 92, p. 233-228, 2011. https://doi.org/10.1016/i.jenvman.2010.09.0 $\underline{08}$

HWANG, I. H. et al. Characteristics of leachate from pyrolysis residue of sewage sludge. Chemosphere, v. 68, n. 10 , p. 19131919, 2007. https://doi.org/10.1016/i.chemosphere.2007 .02 .060

IBGE. Manual técnico de pedologia, Coordenação de Recursos Naturais e Estudos Ambientais. 2 ed. Rio de Janeiro: IBGE, 2007.

INSTITUTO TRATA BRASIL (Brasil). Estudo Trata Brasil "Ociosidade das Redes de Esgoto" 2015. Disponível em: 
http://www.tratabrasil.org.br/saneamento/p rincipais-estatisticas/no-brasil/esgoto. Acesso em: 08 ago. 2018.

JOSEPH, S. D. et al. An investigation into the reactions of biocharin soil. Australian Journal of Soil Research, Victoria, v. 48, n. 7, p. 501515, 2010. https://doi.org/10.1071/SR10009

JOSEPH, S. D. et al. Developing biochar classification and test methods. In: LEHMANN, J.; JOSEPH, S. (Ed.). Biochar for environmental management science and technology. New York: Earthscan, 2009. p. 107-126.

JUNIO, G.; et al. Produtividade de milho adubado com composto de lodo de esgoto e fosfato natural de Gafsa. Revista Brasileira de Engenharia Agrícola e Ambiental, Campina Grande, v. 17, n. 7, p. 706-712, 2013. https://doi.org/10.1590/S1415-

$\underline{43662013000700003}$

KATAYAMA V., et al. Quantificação da produção de lodo de estações de tratamento de água de ciclo completo: uma análise crítica. Eng Sanit Ambient, v.20 n.4, p. 559569, 2015. https://doi.org/10.1590/S1413$\underline{41522015020040105046}$

KIM, K. H.; KIM, J.Y.; CHO, T.S.; CHOI, J.W. Influence of pyrolysis temperature on physicochemical properties of biochar obtained from the fast pyrolysis of pitch pine (Pinus rigida). Biores Technol., v. 118, p. 15862.

2012.

https://doi.org/10.1016/i.biortech.2012.04.0 $\underline{94}$

LEHMANN, J.; GAUNT, J.; RONDON, M. Biochar sequestration in terrestrial Ecosystems: a review. Mitigation and Adaptation Strategies for Global Change. Springer, $n$. 11 p. 403-427, 2006. https://doi.org/10.1007/s11027-005-9006-5

LIU, T.; LIU, B.; ZHANG, W. Nutrients and heavy metals in biochar produced by sewage sludge pyrolysis: its application in soil amendment. Polish Journal of Environmental Studies, Poland, v. 23, n. 1, p. 271- 275, 2014

LOBO, T.; GASSI FILHO, H.; KUMMER, A. Aplicações sucessivas de lodo de esgoto no girasol e efeito residual no trigo e triticale. Revista Brasileira de Engenharia Agrícola e Ambiental, Campina Grande, v. 18, n. 9, p. 881-886, 2014. https://doi.org/10.1590/18071929/agriambi.v18n09p881-886

LOPES, A.; GUILHERME L. Uso eficiente de fertilizantes e corretivos agrícolas: aspectos agronômicos. 3.ed. São Paulo: ANDA, 2000.

MARY, G. S. et al. Production, characterization and evaluation of biochar from pod (Pisum sativum), leaf (Brassica oleracea) and peel (Citrus sinensis) wastes. International Journal of Recycling of Organic Waste in Agriculture, New York, v. 5, n. 1, p. 43-53, Mar. 2016. https://doi.org/10.1007/s40093-016-0116-8

MAŠEK, O.; BROWNSORT, P.; CROSS, A.; SOHI, S. Influence of production conditions on the yield and environmental stability of biochar. Fuel, v. 103, 2013. https://doi.org/10.1016/i.fuel.2011.08.044

NEUSATZ GUILHEN, S. Síntese e caracterização de biocarvão a partir do resíduo de coco de macaúba para remoção de urânio de soluções aquosas. 2018. 324p. Tese (Doutorado em Tecnologia Nuclear), Instituto de Pesquisas Energéticas e Nucleares, IPEN-CNEN/SP, São Paulo. Dispónil em www.teses.usp.br. Acesso em: 29/05/2019

NÓBREGA, Isis P. C.; Efeitos do Biochar nas propriedades físicas e químicas do solo: Sequestro de carbono no solo. 38pg. 2011. Dissertação para obtenção do grau de Mestre em Mestrado em Engenharia do AmbienteInstituto Superior de Agronomia da Universidade Técnica de Lisboa, Lisboa, 2011. 
PINHEIRO, P. C. C.; FIGUEIREDO, F . J.; SÈYE, O. Influência da temperatura e da taxa de aquecimento da carbonização nas propriedades do carvão vegetal de Eucalyptus. Biomassa \& Energia, v. 2, n. 2, p. 159-168, 2005.

PIRES, A. Produção e caracterização de palha de cana-de-açucar (Saccharum sp.) em Sorocaba-SP. 2017. 42 f. Dissertação (Mestrado em Ciência dos Materiais) Universidade Federal de São Carlos, campus Sorocaba Disponível em: < https://repositorio.ufscar.br/bitstream/handl e/ufscar/9192/Vers\%C3\%A3o\%20Final\%20PD F.pdf?sequence=1>. Acesso em: 08 jul. 2018.

PIRES, A.; ANDRADE, C. Recomendação de dose de lodo de esgoto: a questão do nitrogênio. Comunicado técnico, EMBRAPA, 2014. 7p

POGGIANI, F.; GUEDES, M.; BENEDETTI, V. Aplicabilidade de biossólido em plantações florestais: I. Reflexo no Ciclo dos Nutrientes. In: BETTIOL, W. e CAMARGO, O. A. (Eds) Impacto Ambiental do Uso Agricola do Lada de Esgoto. Jaguariúna: EMBRAPA Meio Ambiente, 2000, cap. 8, p. $163-178$.

POGGIANI, F.; SILVA, P. Biossólido aumenta produtividade de eucalipto. Visão Agrícola, no4, p. 105 - 107, 2005. Disponível em: < http://www.esalq.usp.br/visaoagricola/sites/ default/files/va04-ciencia-e-tecnologia09.pdf > Acesso em: 15 mai. 2018.

PROCESSOS QUÍMICOS INDUSTRIAIS:
Fertilizantes. http://www.dequi.eel.usp.br/ acsilva/10\%20 -\%20Fertilizantes.pdf. Acesso em: 06 maio 2018.

RAIJ, B. Van., ANDRADE, J.C., CANTARELLA, H., QUAGGIO, J.A. (ed.). Análise química para avaliação da fertilidade de solos tropicais. Campinas: Instituto Agronômico, 2001. 285p.
RAJKOVICH, S.; ENDERS, A.; HANLEY, K.; HYLAND, C.; ZIMMERMAN, A.R.; LEHMANN, J. Corn growth and nitrogen nutrition after additions of biochars with varying properties to a temperate soil. Biology and Fertility of Soils, New York, v. 48, p. 271-284, 2011. https://doi.org/10.1007/s00374-011-0624-7

SINGH, B. P. et al. Influence of Biochars on nitrous oxide emission and nitrogen leaching from two contrasting soils. Journal of Environment Quality, v. 39, n. 4, p. 1224, 2010. https://doi.org/10.2134/jeq2009.0138

SOUSA, A. Biochar de lodo de esgoto: efeitos no solo e na planta no cultivo de rabanete. Brasília: UnB, 2015. 63p.

SOUZA, J.; LIMA, T. Uso de lodo de esgoto como alternativa ao uso de adubos guímicos em solos arenosos e de baixa fertilidade natural. Presidente Prudente - SP: Unoeste, 2017. 27p.

TAMANINI, C.; et al. Land reclamation recovery with the sewage sludge use. Brazilian Archives of Biology and Technology, v. 51, n. 4, p. 643-655, 2008. https://doi.org/10.1590/S151689132008000400023

TRUGILHO, P. F.; SILVA, D. A. da. Influência da temperatura final de carbonização nas características físicas e químicas do carvão vegetal de Jatobá (Himenea courbaril L.). Scientia Agraria, Piracicaba, v. 2, n. $1 / 2, \quad 2001$.

https://doi.org/10.5380/rsa.v2i1.976

VALE, A. T. do et al. Charactherization of biomass energy and carbonization of coffee grains (Coffea arabica, L) and (Cedrelinga catenaeformis), duke wood residues. Cerne, Lavras, v. 13, p. 416-420, 2007.

VEIGA, T.L.R. Síntese e caracterização de biocarvões de biomassa de casca de café e de madeira de eucalipto. Dissertação 
(Mestrado)- Universidade Federal de Lavras, 2016.

YUAN, H. et al. Influence of temperature on product distribution and biochar properties by municipal sludge pyrolysis. Journal Material Cycles Waste Management, p. 361375, 2013. https://doi.org/10.1007/s10163$\underline{013-0126-9}$

ZELAYA, K. Caracterização de biocarvão de lodo de esgoto e bagaço de cana-de-açúcar e efeitos no cultivo de beterraba. Montes Claros: UFMG, 2016. 72p.

ZHANG, A. et al. Effect of biochar amendment on maize yield and greenhouse gas emissions from a soil organic carbon poor calcareous loamy soil from Central China Plain. Plant and Soil, Dordrecht, v. 351, n. $1 / 2$, p. 263-275, 2012. https://doi.org/10.1007/s11104-011-0957-x

ZHAO, L. et al. Heterogeneity of biochar properties as a function of feedstock sources and production temperatures.Journal of Hazardous Materials, Amsterdam, v. 256/257, p. 1-9, July 2013. https://doi.org/10.1016/i.jhazmat.2013.04.0 $\underline{15}$ 